\title{
Um enigma masculino: Interrogando a masculinidade da desigualdade racial no Brasil ${ }^{1}$
}

\author{
Osmundo Pinho \\ Universidade Federal do Recôncavo da Bahia, Bahia, Brasil ${ }^{3}$ \\ osmundopinho@uol.com.br \\ Recibido: 22 de julio de 2013 \\ Aceptado: 23 de septiembre de 2013
}

1 Artigo de reflexão baseado em pesquisa de campo-piloto de natureza etnográfica, realizada pelo autor e equipe de estudantes sob o marco do Projeto de Pesquisa Multicêntrica "Transmissibilidade Intergeracional, Pobreza, Desigualdade Racial: Visões e Percepções”, coordenado pela Fundação Joaquim Nabuco (FUNDAJ) com recursos do Conselho Nacional de Desenvolvimento Científico e Tecnológico (CNPq) do Governo Brasileiro. Esse artigo está baseado em apresentação realizada no Simpósio "Cuestiones raciales en la era del multiculturalismo. Perspectivas desde Colombia y América Latina”, ocorrido durante o XIV Congreso de Antropologia em Medellín, Colômbia. Agradecemos aos coordenadores Mara Viveros Vigoya e Sergio Lesmes Espinel a acolhida e os comentários, assim como a Franklin Gil Hernández. Discutimos anteriormente o mesmo trabalho no Seminário "Os Significados da Educação entre Duas Gerações: Gênero, Raça, Desigualdades e Expectativas", ocorrido na cidade de Cachoeira, Brasil, agradecemos os comentários dos colegas presentes, notadamente Carlos Augusto Sant'Anna Guimarães, Rosana Heringer, Luiz Flávio Godinho e Georgina Gonçalves.

2 Doutor em Ciências Sociais, UNICAMP (2003).

3 Professor adjunto no Centro de Artes, Humanidades e Letras da Universidade Federal do Recôncavo da Bahia, campus de Cachoeira e no Programa de Pós-Graduação em Ciências Sociais da mesma universidade. 


\title{
Un enigma masculino: interrogando las masculinidades de la desigualdad racial en Brasil
}

\section{Resumen:}

Este artículo reflexiona y discute resultados parciales de una indagación exploratoria realizada en las ciudades hermanas de Cachoeira y São Félix, en el estado brasileño de Bahía. Dicha exploración hizo parte de un esfuerzo multicéntrico de investigación coordinado por la Fundación Joaquín Nabuco (FUNDAJ), entidad federal de investigación con sede en Recife, Pernambuco, Brasil. El proyecto de investigación "Transmisibilidad Intergeneracional: Pobreza y Desigualdad Racial: visiones y percepciones", coordinado por la FUNDAJ, buscaba explorar en seis estados del Noroeste brasileño (la región más pobre y más negra del país) las variaciones de las expectativas sobre educación para padres e hijos desde una perspectiva cualitativa atenta a los significados socialmente producidos y controlando raza/color. Los resultados preliminares indican que las dimensiones de género deben ser consideradas seriamente para interrogar la formación de las identidades raciales en contextos populares y, principalmente, la relación de los jóvenes con la escuela.

Palabras clave: Masculinidades, Escuela, Identidades sociales, Raza, Desigualdades.

Palabras clave descriptores: Masculinidad en la cultura popular, Identidad nacional, Raza negra, negros-identidad racial, Desigualdad cultural, Brasil

\section{A Male Enigma: Examining the Masculinities of the Racial Inequality in Brazil}

\begin{abstract}
This paper reflects and discusses the partial results of an exploratory investigation carried out in the sister cities of Cachoeira and São Felix, in the Brazilian state of Bahia. Such exploration was part of a multicenter research effort coordinated by the Joaquim Nabuco Foundation (FUNDAJ), a federal investigation entity with its head office in Recife, Pernambuco, Brazil. The research project "Intergenerational Transferability: Poverty and Racial Inequality: visions and perceptions", coordinated by the FUNDAJ, sought to explore in six Brazilian states from the Northwest (the poorest region of the country with the highest quantity of black inhabitants) the variations of the education expectations of parents and children from a qualitative perspective attentive to socially produced meanings and controlling race / color. Preliminary results indicate that the gender dimensions must be considered seriously for questioning the formation of racial identities in popular contexts and, particularly, the relationship of youth with school.
\end{abstract}

Keywords: Masculinities, School, Social Identities, Race, Inequalities.

Key words plus: Masculinity In Popular Culture, National Identity, Black Race, Black-Racial Identity, Cultural Inequality, Brazil

\section{Um Enigma Masculino: Interrogando a Masculinidade da Desigualdade Racial no Brasil}

\begin{abstract}
Resumo
Este artigo reflete e discute resultados parciais de uma investigação exploratória realizada nas cidades irmãs de Cachoeira e São Félix, no estado brasileiro da Bahia. Tal exploração fez parte de um esforço multicêntrico de pesquisa coordenado pela Fundação Joaquim Nabuco (FUNDAJ), órgão federal de pesquisa sediado no Recife, em Pernambuco, Brasil. O projeto de pesquisa "Transmissibilidade Intergeracional: Pobreza e Desigualdade Racial: visões e percepções”, coordenado pela FUNDAJ, visava explorar em seis estados do Nordeste brasileiro (a região mais pobre e mais negra do país), de uma perspectiva qualitativa, atenta aos significados socialmente produzidos, variações das expectativas sobre educação para pais e filhos, controlando-se raça/cor. Os resultados preliminares indicam que as dimensões de gênero devem ser consideradas seriamente para interrogar a formação das identidades raciais em contextos populares e, principalmente, a relação dos jovens com a escola.

Palavras-chave: Masculinidades, Escola, Identidades sociais, Raça, Desigualdades.

Palavras-chave descritores: Masculinidade na cultura popular, Identidade nacional, Identidade negra, Black-racial, Desigualdade cultural, Brasil.
\end{abstract}




\section{Introdução}

Este artigo reflete e discute resultados parciais de uma investigação exploratória realizada nas cidades irmãs de Cachoeira e São Félix, no estado brasileiro da Bahia. Tal exploração fez parte de um esforço multicêntrico de pesquisa coordenado pela Fundação Joaquim Nabuco (FUNDAJ), órgão federal de pesquisa sediado no Recife, em Pernambuco, Brasil ${ }^{4}$. O projeto de pesquisa "Transmissibilidade Intergeracional: Pobreza e Desigualdade Racial: visões e percepções”, coordenado pela FUNDAJ, visava explorar em seis estados do Nordeste brasileiro (a região mais pobre e mais negra do país), de uma perspectiva qualitativa, atenta aos significados socialmente produzidos, variações e modulações das expectativas sobre a educação para pais e filhos, controlando-se raça/cor. A nós coube realizar a etapa piloto para o estado da Bahia.

Seguindo o preconizado por Hasenbalg e Silva (2003) e outros autores, como a necessidade de colocar em evidência a articulação causal entre as diversas dimensões das desigualdades observáveis no decurso das etapas do ciclo da vida individual e familiar, (Hasenbalg e Silva, 2003) o Projeto Transmissibilidade Intergeracional buscou interrogar sociologicamente as principais transições que o jovem realiza na sua transição da adolescência para a vida adulta levando em conta a potencialidade de superacão ou transmissão da pobreza e estruturas de desigualdade. Como apontado de modo claro no próprio projeto original:

A intenção desta proposta de pesquisa é investigar os determinantes da desigualdade educacional entre jovens. Daremos ênfase às interações entre raça e classe social como efeitos nas escolhas de continuar ou desistir de prosseguir no sistema educacional. (Fundaj, 2009, p. 4)

Desse modo, a etapa do projeto que realizamos, definiu-se como abordagem qualitativa, interessada em flagrar e interpretar valores associados as "escolhas de continuar ou desistir", levando em conta as diferenças entre as gerações.

O projeto em Cachoeira/ São Félix foi desenvolvido como um projeto-piloto, no qual a equipe que coordenamos entrevistou 12 pares

4 Agradecemos a generosidade e parceria de Carlos Augusto Sant'Anna Guimarães, um dos coordenadores do projeto na FUNDAJ e nosso principal interlocutor nesse processo. 
intergeracionais ${ }^{5}$, interrogando sobre experiências e perspectivas ligadas a educação, discriminação, preconceito e cotidiano/desempenho escolar. De modo que o que aqui brevemente discutimos está referido a esse universo empírico. Em virtude de nosso interesse particular em questões de gênero e masculinidade demos determinada inflexão a análise, que salientasse justamente a conexão de nossos dados com a discussão desses temas. Os resultados para os outros estados ainda está sendo analisados e logo serão divulgados pela equipe responsável na FUNDAJ.

No que segue abaixo iremos apresentar brevemente dados sobre desigualdades raciais na sociedade brasileira e no campo da educação, buscando por ênfase nas intersecções com desigualdades de gênero, de modo a por relevo em determinadas características peculiares do universo masculino nesse contexto. Faremos rápida discussão conceitual sobre desigualdade de gênero, assim como sobre os significados socialmente construídos para a masculinidade no Brasil, para ao final discutir algo de nosso dados para Cachoeira e São Félix. O nosso trabalho sobre masculinidade, raça e educação em Cachoeira e São Félix deve continuar e necessita aprofundamento, mas já nos parece claro que dimensões de gênero devem ser consideradas seriamente para interrogar a formação das identidades raciais em contextos populares e a relação dos jovens com a escola, como esperamos poder indicar.

\section{Desigualdade e cultura}

Como ponto de partida crítico mais geral levamos em consideração determinada dualidade ou inconsistência entre o que poderíamos qualificar como a sociologia da desigualdade racial e a etnografia da cultura negra.

Reconheceríamos como se consolidou certa divisão acadêmica do trabalho nesse campo. Se, notadamente com o Ciclo da UNESCO e o convênio Columbia/Estado da Bahia, nos anos 50, a sociologia brasileira dedicou-se a flagrar com recursos metodológicos específicos, como o uso de estatísticas e dados agregados, padrões impessoais de desigualdade que se descreveriam como de base racial, a antropologia, caudatária da tradição dos estudos afro-brasileiros, dedicou-se, nos

Agradecemos o excelente trabalho dos estudantes da equipe: Alane Reis, Fred Igor Santiago e Tainara Silva. Assim como a Reitoria da UFRB que nos garantiu as condições para a realização da pesquisa. 
anos heroicos de formação da disciplina, e até bem pouco tempo atrás, à documentação de aspectos culturais - ou seja, estruturas simbólicas performadas - justamente aquilo que se instituiu canonicamente como Cultura Negra nos anos 30 (Maio, 1999; Pinho, 2007).

Ora, assim, enquanto de um ponto de vista quantitativo, ou interessado em grandes estruturas sociais, nos defrontamos com uma sociedade praticamente divida em duas pela "linha de cor" socioeconômica; do ponto de vista dos estudos antropológicos ou qualitativos, observamos a confirmação da perspectiva êmica, qual seja, a prevalência da miscigenação como dissolvente de tensões sócio-raciais, a convivência pacífica entre os sujeitos racializados, e padrões flexiveis de relações raciais interpessoais, favorecido pelo continuum de cor.

Tudo se passa como se a constituição da "diferença" negra, como diferença cultural, não estivesse implicada na localização dos sujeitos sociais negros concretos num espaço de lutas e de desigualdade, que é efetivamente estruturado. Como se a cultura fosse essa entidade etérea, "like the air we breath" (Foucault, citado em Dreyfus e Rabinow, 1982, p. 49), coleção arbitrária de itens, arrolados pelos que se arrogam especialistas culturais (e nesse caso poderiamos incluir não só antropólogos, mas artistas, jornalistas e intelectuais num sentido amplo). Como se a oposição entre cultura e sociedade, ou estrutura e prática, fosse absoluta e não devedora de determinada acomodação epistemológica, corolário das distinções ocidentais.

Como aponta Sahlins (1990), no campo da antropologia tais oposições parecem bem estabelecidas no duplo legado do funcionalismo e do estruturalismo, que nos faz esquecer a verdadeira natureza da ação simbólica, na qual o conjunto duplo do passado inescapável e do presente irredutivel, molda as condições por meio das quais os signos, conceitos e categorias são atuados praticamente, e nas quais os agentes são autores de seus próprios conceitos. Sahlins propõem, dessa forma, que levemos em conta o que ele chama de "estrutura da conjuntura", como uma sociologia de situação das categorias culturais, que nos permitiria descrever os modos práticos de atuação cultural que põem em movimento a estrutura social.

Tal reconciliação favoreceria uma visão da cultura, que influenciada pelos Estudos Culturais (Clarke, Hall, Jefferson e Roberts, 1975), detestados por Sahlins, não veria a cultura como o destino inexorável dos sujeitos, mas como o território de convergências e lutas, pondo em relevo seus aspectos históricos e políticos, em oposição a uma visão, digamos, mítica da cultura, que a concebe como 
um conjunto de elementos a-históricos, ordenados segundo princípios estruturais abstratos. Entretanto, como diria Paul Gilroy: "the terrain of meaning and action is also a field of historical development trough struggle" (Gilroy, 1987). Tal visão mítica certamente favorece que releguemos ao negro o papel de mero portador da cultura e não de um ser histórico, presente nas lutas sociais (e culturais), inclusive naquelas que conformam o mesmo campo acadêmico que o elegeu como objeto. Assim, tal disposição crítica, ainda que eventualmente eivada de imprecisão e voluntarismo, aponta um caminho para contestação da referida dualidade.

Mas é para a referida incongruência, ou ponto cego, entre a sociologia das desigualdades educacionais/raciais e a produção da masculinidade como ação significativa prática, que voltamos nosso interesse crítico nesse trabalho, para justamente discutir o que chamariamos de enigma masculino no desempenho educacional.

\section{Sobre raça e masculinidade(s)}

A baixa incidência de luz crítica cria a ilusão de que as formas sociais de produção e regulação de performances e identidade masculinas permanecem no ponto cego da auto-reprodução da sociedade e de suas formas simbólicas. Todavia, devemos reconhecer o intenso investimento social e politico para a criação/reprodução de identidades e posições de sujeito masculinas, no âmbito da própria auto-fabricação da vida social em suas contradições e ambiguidades. Não só é a masculinidade vivida no mundo da vida, na esfera pública e nas transformações de intimidade, onde aparece como socialmente regulada, mas a própria sociedade ganha corpo e densidade, no gesto masculino repetido como a diferença, ou o sem número de diferenças, que produzem o cortejo das representações performadas de gênero (Arilha, Unbehaum e Medrado, 2001; Connel, 2005; Cornwall e Lindsfarne, 1994; Kimmel, 1998).

A "crise do masculino", como poderiamos eventualmente qualifica-la, é uma crise da sociedade, e de suas contradições, que são portadas ou encenadas na própria produção dos vetores de diferenciação social. Tal encarnação não é a mera repetição etérea do "simbólico" ou do "discurso", como se a dimensão significante da vida social pudesse ser facilmente desencaixada da dimensão material, quando todas essas oposições: subjetividade X sociedade; simbólico X material; 
conteúdo X representação; são já o efeito ideológico de uma separação arbitrária, que ganha inteligibilidade ao longo da história, e como a própria arena da história. (Butler, 2003; Baudrillard, 1972; Strathern, 1996). No Novo Mundo, de um modo em geral, e no Brasil com dramaticidade particular, as relações de parentesco e gênero entre africanos escravizados e seus descendentes, tem sido objeto a muito tempo, de vigilância, patologização e mesmo criminalização por parte do Estado. (Cohen, 2001; 1999; Vainfas, 1997; Stolke, 2006; Malebranche, 2006).

Considerar as masculinidades racializadas como operantes em ambientes construídos por relações de gênero implica por outro lado em reconhecer a efetividade da regulação (estatal ou não ) de gênero para os homens. Em "Gender Regulations", Judith Butler, diz: "gender requires and institutes its own distinctive regulatory and disciplinary regime" (Butler, 2004, p. 41). Porque "the norms that govern those regulations exceed the very instances in which they are embodied" (p. 40). De tal modo, que a passagem de princípios abstratos para a norma, se incorpora por meio da regulação de sujeitos históricos particulares. A regulação, diz a autora, não apenas constitui os sujeitos, mas possibilidade de sua localização ou posicionamento numa ordem determinada, interiorizada como a própria produção do lugar do sujeito.

Procurariamos, dessa forma, considerar o ponto de vista dos "nativos" em questão, jovens homens negros em Cachoeira (e sua irmã São Félix), histórica cidade colonial a $110 \mathrm{~km}$ de Salvador, buscando também qualificar a perspectiva socialmente enraizada desses sujeitos, justamente assujeitados pelos discursos e práticas raciais e de classe, que são a máquina de produção de subjetividades e identidades sociais em nossa sociedade, racializada e marcada pela colonialidade do poder (Quijano, 2007; Maldonado-Torres, 2007).

As formas de representação ou de cultura popular, agenciadas em contextos estruturados pela desigualdade racial, as estruturas de classe e o sistema sexo-gênero, são matéria privilegiada de elaboração da identidade e de representação social desses grupos masculinos juvenis, como a literatura aponta, e não a escola (Alvito, 2001; Cecchetto, 1997; 2004; Mattos, 2006). Sendo o gênero a modalidade em que a raça é vivida, a masculinidade negra porta, portanto, suas próprias contradições. Como, por exemplo, o embodyment de uma cultura de compensação para homens negros, mantidos constantemente sob tensão racial, emasculados pelo racismo, subjugados pelas estruturas de classe, coagidos pelo sistema sexo-gênero, aprisionados em meios a discursos 
militarizados, do mercado e da criminalização (Amar, 2003; Collins, 2005; Hooks, 2004; Souza, 2010).

Definidas dessa forma, as prerrogativas para masculinidades racializadas em contextos populares, deveriamos interrogar de que formas essas condicionantes interagem com ao ambiente escolar e suas exigências, bem caracterizadas pelo que Bourdieu e Passeron (2010), chamaram de a "reprodução", como inculcação por meio da violência simbólica de um "arbitrário cultural".

\section{Articulações contraditórias de raça e gênero}

Num artigo já clássico Fúlvia Rosemberg aponta e discute determinadas articulações contraditórias de raça e gênero, que nos permitem lançar luz sobre as dicotomias apresentadas acima e que nos forçam a buscar modelos alternativos para compressão da reprodução de desigualdades sociais, flagrados em termos estatísticos, mas pouco claras em termos microssociológicos.

A pergunta de Rosemberg é clara e nos serve de guia e provocação: "Como as hierarquias de gênero interagem com as de raça e classe para produzir um sistema educacional tão excludente como o brasileiro?". (Rosemberg, 2001, p. 518)

As respostas disponiveis parecem insuficientes por uma serie de motivos. Manejam, em primeiro lugar, o modelo essencialista da " $d u-$ pla desvantagem" ("ter nascido pobre e mulher"), configurando modo algo fatalista e automático, a correlação entre desigualdades, e notadamente a desigualdade educacional e o gênero, a partir de indicadores que pecam por seu caráter excessivamente geral ou global, ou inversamente por sua fragmentação. A unilineariedade das analises baliza a adoção de metas uniformes para politicas educacionais, sem consideração de variáveis locais, regionais, raciais, de gênero, de classe e outras, fazendo da dominação de gênero tábula rasa, intransparente a outros determinantes da vida social.

Rosemberg insiste, ao perguntar: a dominação de gênero assume contornos equivalentes em todas as instituições sociais? Em todas as fases da vida? Significa sempre discriminação contra as mulheres? 
Devemos incorporar de modo significativo na análise, sem dúvida, a diferença de renda registrada entre os grupos de raça/gênero. Que, como veremos, preserva e revela a persistência de uma distância muito grande entre a renda dos homens brancos e a dos demais grupos. De tal modo, vemos que em 1996 os homens brancos recebiam, em média, 1,76 vezes a mais que as mulheres brancas. Em relação aos homens negros, os homens brancos recebiam 2,21 vezes mais. A mulher negra apresentava renda média 3,70 vezes menor que a do homem branco ${ }^{6}$.

Como parece claro, levando em conta os dados, não haveria uma correlação linear e, como os estudos de interseccionalidade apontam (Creenshaw, 1995), a articulação concreta e historicamente consolidada entre raça e gênero não segue um modelo único cumulativo de desigualdades, mas apresenta padrões diferenciais resultantes da interação de fatores complexos, como Rosemberg aponta. As mulheres, em sociedades multirraciais como a nossa, marcadas pelo racismo e pela desigualdade estruturante, são, dentre outras coisas, membros de grupos sociais racializados e suas realizações educacionais refletem esses condicionamentos estruturais de modo diferenciais. Mas ora, e o que se passa com os homens?

O que aparece convencionado na literatura como "a defasagem dos rapazes" nos indica um padrão desigual de desempenho educacional dos homens vis-à-vis as mulheres. As razões para esses resultados configuram a parte sociológica, digamos assim, do enigma masculino que buscamos interrogar.

Os dados da PNAD 2006 (Pesquisa Nacional por Amostra de Domicilio) nos mostram um retrato mais preciso, focado justamente no que chamamos de "defasagem dos rapazes". A proporção de desfasados na faixa mais elevada de idade nos mostra uma diferença de mais de dez pontos percentuais. Ou seja, na faixa de 14 anos, mas de seis dentre cada dez rapazes estaria defasado na correlação idade/anos de estudo, contra pouco mais de cinco mulheres.

A distribuição por raça/cor também nos revela dados significativos que indicam a incidência de variações de gênero com prejuizo para os homens. Enquanto os homens brancos estão defasados em torno de $40 \%$ contra as mulheres brancas, para os homens negros a defasagem é bem maior, para cada dez homens negros, mais de seis

6 Utilizamos dados apresentados em Rosenberg: 2001; IPEA: 2009, provenientes dos censos demográficos decenais promovidos pelo governo federal quanto de pesquisas domiciliares amostrais, como a PNAD. 
estariam defasados, enquanto que as mulheres negras apresentam defasagem próxima a $5 \%$, superior, entretanto a aquela encontrada entre os homens brancos. Dessa forma, as mulheres brancas apresentaram o menor índice de defasagem, e o os homens negros o pior. Essa configuração reclama por interpretações mais refinadas que escapem a unilineariedade e ao automatismo denunciados por Rosenberg.

Um sem numero de explicações tem sido arrolado para enfrentar essa dificuldade. Alguns autores sugerem que no caso há o fato de que pais pobres insistem mais na educação dos meninos, produzindo maior repetência e continuidade do atraso, evitando assim a evasão. Outros indicam a entrada precoce no mercado de trabalho das crianças e adolescentes do sexo masculino, um argumento muito disseminado, e que encontra eco nas percepções do senso comum. Por razões de gênero, os rapazes precisam dividir o tempo da escola com o tempo do trabalho, porque os homens precisariam constituir-se logo como provedores e tem para o salário destinação mais urgente que as mulheres, que podem, em função dos ideais de gênero, depender economicamente de seu pai ou marido. De todo modo, diria Rosenberg e outros, seguimos lidando com dados pobres, diluídos e pequena retaguarda de produção acadêmica, confrontando um "vale-tudo" de interpretações associadas a percepções do senso comum.

\section{Juventude desigual e trabalho doméstico}

Segundo dados publicados pelo IPEA no "Comunicado da Presidência $\mathrm{n}^{\circ} 36$ - PNAD 2008: Primeiras Análises - Juventude - Desigualdade racial" (2009) o jovem adolescente brasileiro (15 a 17 anos) tem diminuído sua participação no mercado de trabalho. Nos últimos 10 anos, a taxa de participação no mercado de trabalho caiu de 45\%, em 1998, para $37 \%$, em 2008. Os homens, geralmente, mais do que as mulheres, sofreriam grande pressão para entrarem precocemente no mundo do trabalho. Os dados apresentados indicam que em dez anos o percentual dos homens jovens que só trabalham permaneceu entre 55 pontos percentuais. Dentre todos os jovens dessa categoria, os que apenas estudam representam, entretanto, aproximadamente somente $10 \%$ para todo o periodo. A situação das mulheres é bem diferente. Oscila entre 20 e $15 \%$ o número de meninas que apenas estuda e não trabalha.

Os dados nos mostram um quadro de contrates entre a inserção masculina e feminina para jovens entre 18 e 24 anos, que conformaria 
a hipótese de que os rapazes têm pior desempenho escolar, porque estariam sendo puxados precocemente pelo mercado de trabalho.

Se introduzirmos, entretanto o trabalho doméstico na equação as coisas tornam-se mais complexas, o que nos permitiria ressaltar a importância do trabalho doméstico para definição de lugares estruturais da diferença para o gênero na sociedade brasileira.

Segundo estudo de Amélia Cristina Abreu Artes e Marília Pinto de Carvalho, no Brasil, em 2007, 89,9\% das mulheres com 16 anos ou mais afirmavam cuidar de afazeres domésticos e somente $50,7 \%$ dos homens o faziam. Enquanto as mulheres dedicavam, em média, 27,2 horas por semana a essas atividades, os homens dedicavam 10,6 horas. Na faixa etária dos 10 aos 14 anos, as meninas gastavam aproximadamente 14 horas semanais em afazeres domésticos, enquanto os meninos disponibilizavam menos de 9 horas. Do mesmo modo, comentam a autoras, a frequência à escola é mais presente no universo feminino e diminui com a idade. Enquanto aos 10 anos 99,1\% das meninas e $98,4 \%$ dos meninos frequentam a escola, este índice diminui para $94,1 \%$ e $93,6 \%$, respectivamente, aos 14 anos. Uma tendência como essa, verificada aqui, uma vez generalizada explicaria a ausência das meninas na escola na faixa de idade entre 18 aos 24 anos.

Entretanto, e significativamente, uma parcela importante dos jovens que não estudam, também está fora do mundo do trabalho: $28,7 \%$ dos meninos e $11,7 \%$ das meninas. Se o trabalho é apresentado como a principal justificativa para o abandono escolar, como explicar, então, que mais de 76 mil rapazes do grupo pesquisado por não frequentam a escola e não trabalham?

Assim, quanto mais incorporamos elementos na análise, mais complicado fica o nosso enigma masculino, e mais claro torna-se a imbricação fundamental entre os padrões de reprodução social da sociedade, e a categorização racializada de gênero, conformando efetivamente dispositivos de articulação das trajetórias individuais a padrões estruturais mais gerais. Poderiamos considerar, e essa é efetivamente a nossa perspectiva, que a produção e sustentação de significados socialmente definidos para masculinidade jogaria peso importante na reprodução estrutural do sistema. Ou seja, seria para a articulação que engendra o vínculo entre a cultura (rede de categorias e sentido) e a estrutura social, como padrões persistentes, que voltaríamos nosso olhar. 


\section{Perfis juvenis $^{7}$}

Com base nos relatórios de campo, produzidos pelos estudantes-bolsistas do projeto apresentamos algo do perfil dos jovens homens entrevistados, moradores das cidades de Cachoeira e São Félix, selecionados por meio da técnica conhecida como "bola-de-neve", ou seja os entrevistados indicam conhecidos e amigos.

R.R.A é um cachoeirano negro de 23 anos, morador da Zona Rural da cidade, trabalha 44 horas semanais para sustentar o curso de Enfermagem na Faculdade Adventista da Bahia,e não hesita ao responder a sua cor/raça. A mãe, que possui o ensino médio completo, nunca trabalhou remuneradamente após o casamento. Seu pai, único provedor da casa possui ensino médio incompleto. O jovem sempre estudou em colégios da rede pública e hoje cursa sua graduação em uma instituição privada. Foi alfabetizado aos 10 anos de idade. Segundo o observado tratar-se-ia de uma família negra classe média, que ascendeu economicamente mais não prioriza a educação escolar para os filhos. Uma casa grande, muitos móveis e eletrodomésticos na garage um carro é importado. O pai e os dois irmãos mais velhos são trabalhadores terceirizados da Petrobrás, o pai possui um cargo de chefia e R.R.A., o filho mais jovem é estudante universitário de uma Universidade particular, como dissemos.

R.R.A. explica o que motivou a fazer curso superior: "Em primeiro lugar meus pais, em segundo, fiquei muito observando assim a vida de meu pai, meus irmãos, no qual nenhum tem nivel superior, e eu vejo o grau de dificuldade pra arranjar um trabalho".

Nesse momento, R.R.A. coloca que enxerga no curso superior uma oportunidade de conseguir empregos melhores que o do pai e dos irmãos, e em nenhum momento cita a mãe, que como já foi dito anteriormente nunca trabalhou remuneradamente.

O nosso jovem mora desde que nasceu em Capoeiruçu, distrito cachoeirano, que a cerca de 20 anos passou a sediar o IAENE (Instituto Adventista de Educação do Nordeste), uma instituição privada evangélica que oferece do ensino fundamental ao superior. A grande maioria dos estudantes dessa instituição é de outros estados do país, que moram e estudam no IAENE pelo regime de internato. Nos cursos de graduação acontece da mesma forma, estudantes de diversas partes

Essa seção está baseada no relatório produzido pelos estudantes bolsistas do projeto. Os já citados: Alane Reis, Fred Igor Santiago e Tainara Silva. 
do Brasil, em sua maioria brancos, identificados localmente como de classe média e alta. Inserido no ensino superior privado R.R.A. nos responde sobre os sistema de cotas raciais na Universidade Púbica:

Posso até estar sendo ignorante ao falar isso, mas não concordo, porque isso acaba dizendo, pela minha opinião, que o negro em si, o conhecimento dele é inferior ao da cor branca e isso não é, acredito que não seja, entendeu? Isso mostra que a cada dia o negro ele está se deixando a se levar por essas coisas, sendo que ele pode ter uma capacidade de ensino, melhor do que a do branco, só basta ele querer, não importa o colégio que ele estuda, basta a boa vontade dele.

E em seguida parece contradizer-se:

Pergunta: Estando já no ensino superior, dentro da universidade, você acha que as oportunidades de participar de projetos, de galgar coisas melhores, é igual pra todo mundo, negros, brancos, homens e mulheres?

R.R.A.: Olha, é uma pergunta um pouco complicada, posso dizer que não, mas isso depende de cada um de nós, ou seja, devemos correr atrás, porque se facilitar as coisas acaba indo sempre pra alguém prioritário, então se não temos essa prioridade, devemos correr atrás.

Sobre o racismo no Brasil ele responde:

Olha eu sou um pouco radical sobre isso, acho que o maior racista que existe hoje no Brasil é o negro, eu acho ridículo quando o negro ele questiona quando uma pessoa chama ele de negro ou preto, acho que se uma pessoa me chamar de negro ou preto isso seria uma questão de orgulho pra mim, eu me sentiria ofendido se uma pessoa me chamasse de branco, então o negro, querendo ou não, ele demonstra cada dia mais que ele tem vergonha de ser negro.

W.L.C.S., cachoeirano de 18 anos é estudante secundarista e declara-se "pardo", apesar de que ter sido classificado pelo entrevistador como preto.

8 A categoria formal dos institutos de pesquisa do governo brasileiro para "mestiço". Sobre os 
O jovem gosta de fazer piadas, e ao longo da entrevista, parece dificil perceber quando ele está fazendo graça, ou está rindo e mentindo por vergonha em responder, por exemplo quando pergunto que tipo de trabalho o pai dele desempenha, ele demora e responde: "Meu pai trabalha (uma pausa) com turismo". O pai dele na verdade trabalha como topiqueiro - motorista de topique (utilitários para transporte alternativo de pessoas). Mais tarde volto a mencionar sobre seu pai e ele fala: "Meu pai é um cara trabalhador é, rala pra caralho, mas eu não quero ter o mesmo futuro que ele não." Nesse caso diriamos se tratar de uma família negra classe média baixa, a casa é simples, mas bastante aconchegante, não muito espaçosa. Percebemos a importância que a mãe do jovem dá aos estudos dele, que sempre estudou em colégios particulares, ela própria possui ensino superior.

O jovem em todo momento faz questão de enfatizar o seu total desinteresse em estudar, repete sempre as vezes que perdeu o ano, as brigas no colégio, de quando matava aula, e que a única coisa boa que se lembra da escola são as garotas. O que parece é que ele acredita que seu comportamento transgressor, por vezes desordeiro, é atrativo para relacionamentos afetivo/sexuais: "É o que eu estava lhe falando, eu só queria brincar, jogar bola, mulher; nunca me interessei por estudo, velho".

W.L.C.S. diz que pretende ingressar no curso superior ainda no ano que vem, ele fala que está na hora de crescer, não depender mais dos pais. Perguntamos se essa melhora de vida que ele afirma que o ensino superior proporciona vale pra todo mundo, exemplifico falando "negros, brancos, mulheres, homens", ele responde: "Vale com certeza. Porque hoje em dia, no mundo que agente vive, todo mundo é igual. Não tem diferença de raça, de pele, de cor, de nada." E sem seguida também parece contradizer-se: "É uma questão que está sendo discutida viu velho, porque tipo assim, a galera que é muito racista velho, tanto branco com preto, preto com branco, então, o racismo hoje em dia não tem cor, eu acho, todo mundo é racista velho, se for contar todo mundo é racista."

O entrevistado J.S.I. ${ }^{9}$, também classificado como negro, nasceu em Cachoeira, atualmente é estudante do curso de história da Universidade Federal do Recôncavo da Bahia, tem 26 anos e mora com a mãe, que é professora do ensino infantil na cidade da Cachoeira.

sistemas de classificação racial no Brasil Cf. Sansone: 1996.

9 As siglas referem-se a nomes fictícios. 
J.S.I, Entrou na universidade aos 22 anos, depois de ter feito cerca de seis exames vestibulares (que facultam o acesso a universidade pública), teve como principais fatores que o motivaram/inspiraram para o ingresso na universidade o exemplo de professores que o marcaram, parentes que já estavam na universidade e principalmente a insistência de sua mãe, para que ingressasse no nível superior. Nesse contexto seu ingresso na universidade teve/tem uma serie de significados, que permeiam a escolha profissional, a sua percepção enquanto um jovem negro politicamente consciente, sua condição econômica e a percepção de como o racismo vigente na sociedade brasileira, o deixa em uma posição desfavorecida em relação a outros, como nos esclarece muito bem, ao responder. "O que o motivou a fazer o nível superior ?"

Minha condição social... Minha condição social, minha condição cultural e ai... As desigualdades que vem acontecendo e acontecem né? No meio social em que vivo é muito latente, é muito explicito, e eu percebi que eu precisava de um nivel superior pra poder me engajar também no mercado de trabalho, me sobressair na sociedade, tendo em vista que me considero negro e isso é uma barreira e... e o fato de eu ser negro é...isso pressupõe uma barreira muito grande dentro da sociedade que é racista ne?

O entrevistado L.L.M., também de 26 anos é negro, e originário de uma comunidade quilombola (de descendentes de ex-escravos), por muitos anos permaneceu morador da zona rural de Cachoeira, agora é estudante da Universidade Federal do Recôncavo da Bahia e bolsista da assistência estudantil, da referida universidade. Atualmente mora na cidade de Cachoeira, dividindo uma casa com outra estudante também originaria de sua comunidade quilombola. L.L.M nasceu na comunidade quilombola de São Francisco do Paraguaçu, localizada em uma região pesqueira. Seus pais não completaram o ensino fundamental e ambos são pescadores, assim como uma extensa genealogia de sua família. Ele foi o primeiro membro de sua família a completar o ensino médio e adentrar em uma universidade.

Para o jovem, o significado de entrar na universidade, tem uma forte carga de ascensão social e econômica, além de alguma forma significar a possbilidade de "fugir" do árduo oficio, que seus pais, e comunidade que mora, tem como principal forma de subsistência, ou seja, a mariscagem e pescado. Dessa forma, para o entrevistado, cursar um nível superior é mudar de vida, no sentindo socioeconômico do termo 
e conseguir um trabalho, que valorize mais sua capacidade intelectual do que fisica, como podemos observar em sua fala.

Pra mudar de vida mesmo velho, porque minha família toda é humilde e tal e lá poucas pessoas tem oportunidade ou as pessoas vivem da pesca ou do mato as pessoas vão tirar estopa, piaçava do extrativismo vegetal. E ai eu sempre pesquei com meu pai vivia naquela dificuldade ai decidir procurar outra coisa pra fazer eu não agüento muito está vida pesada sabe, eu vou tentar intelectualizar o negocio.

O entrevistado V.S.R., tem 17 anos, negro, é estudante do segundo ano do ensino médio, do colégio Estadual da Cachoeira, cidade onde mora com seus avós e irmã. Este adolescente apresenta um perfil impar. Para ele entrar em uma universidade é um objetivo traçado, planejado e que será efetivado, como nos diz o próprio.

Rapaz eu pretendo concluir o ensino médio e fazer uma faculdade né? Por que hoje a faculdade, se você quiser arranjar um emprego você tem que ter uma faculdade, um curso técnico.

\section{Significados da masculinidade em Cachoeira e São Félix}

Levando em conta o visto acima, interrogariamos de que forma os significados associados as masculinidade são construídos no Brasil, de um modo em geral, e no nos contextos em questão. Mais especificamente, em conformidade a trabalhos como os citados, discutiriamos como formas de masculinidade são construídas internamente à sala de aula. $\mathrm{Ou}$, dito de outro modo, como a sala de aula e a escola são arena ou contexto socialmente estruturado para a performação de identidade de gênero, e sua efetiva construção intersubjetiva. De que maneira, para os meninos e rapazes a escola, a sala de aula, o pátio, e o seu entorno seriam lócus de processos de subjetivação de gênero, independente, ou mesmo para além, dos processos educativos institucionais?

O significado prático de "ser homem", e a forma socialmente estruturada de constituir e objetificar os valores e ideais de masculinidade, estão definidos pela interação dos atores com as inúmeras agências por meio das quais são adquiridos/produzidos/transformados determinados significados, hábitos e práticas atribuídas à conduta masculina. Seria assim, na família, na igreja, nas brincadeiras de crianças, no jogo de futebol, no grupo de amigos, que os sujeitos aprendem a dissociar homens e mulheres (KIimmel, 1998; Alvito, 2001; Souza, 
2010). E também, é obvio, na escola, e talvez mesmo de modo privilegiado, considerando a importância da escola como espaço para construção de grupos de pares. Onde os rapazes, tem a chance de por a prova sua masculinidade e de compará-la a de outros rapazes, competindo, em ambiente restrito, pela posição adequada ou desejada no interior das hierarquias de gênero (e raciais/sexuais). Não podemos descurar, além do mais, do papel da família, ou melhor, dizendo dos pais, e a interação do universo familiar com o universo da escola, em relação, particularmente e de modo específico para o nosso caso, para às diferentes expectativas para meninos e meninas.

Como já dissemos, os dados que temos para Cachoeira e São Félix ${ }^{10}$ são prospectivos e não conclusivos - mas indicam uma atitude diferenciada dos pais com relação ao incentivo dos filhos. O que poderíamos dizer é que em alguma medida cuidar da educação das crianças é coisa da mulher. Como observamos no depoimento de um pai sobre o desempenho escolar da filha:

Ela, ela primeiro, ela estudava aqui no colégio, perdeu o ano, ela perdeu esse último ano agora, ela tá na $7^{\mathrm{a}}$, na $8^{\mathrm{a}}$, ela perdeu a $7^{\mathrm{a}}$, a $6^{a}$ série, ai T. pegou ela e botou em represália, e mandou estudar lá no XXX que é um bom colégio, acho que é em São Félix, esse XXX, é um colégio estadual de fama, mas mandou mais porque é mais longe pra ela ficar né, porque ela perdeu o ano aqui no YYY, que era pago, ela brincou demais, o professor deu queixa que ela não queria nada e tal, aî T., nós participamos lá, fomos lá e discutimos, o professor, eeh, porque quem segue, eu num digo, eu não participo muito, não sei eu não participo muito do currículo escolar das meninas, quem mais é T., minha mulher que segue mais entendeu? (R., 65 anos)

10 Em 2008, o Instituto Brasileiro de Geografia e Estatística (IBGE) estimou a população da cidade de Cachoeira em 32.252 habitantes. Destes, 15.724 são homens e 16.480 mulheres. Estima-se em 2004 que a população na faixa etária de 10 a 19 anos era de 7.350 pessoas. 12.527 tinham entre 20 e 49 anos, ou seja, um terço da população de cachoeira é formado de jovens. Cachoeira, depois de Salvador, é a cidade baiana que reúne o mais importante acervo arquitetônico no estilo barroco. Seu casario, suas igrejas, seus prédios históricos preservam ainda a imagem do Brasil Colonial, tempo em que o comércio e a fertilidade do solo fizeram de Cachoeira a vila mais rica, populosa e uma das mais importantes do Brasil, durante os séculos XVII e XVIII. Os dados do PNUD no Atlas de Desenvolvimento Humano de 2003 conferem ao municipio uma renda per capta no início do segundo milênio de R\$119,5. O Índice de Desenvolvimento Humano Municipal, daquele mesmo período é da ordem de 0,681 , colocando a cidade em $42^{\circ}$ lugar em relação a outros municípios do Estado. Segundo a Secretaria do Planejamento do Estado da Bahia, em 2004 o contingente populacional ocupado no mercado formal de trabalho em Cachoeira, não chegava aos três mil, contabilizando 2.840 pessoas. Destes, cerca 1.234 tinham o ensino médio completo. No que se refere à educação, em 2008 o municipio tinha 5.416 alunos matriculados no ensino fundamental em escolas públicas, e 808 em escolas privadas. No ensino médio, tinha-se 1.596 alunos matriculados, destes, 957 encontravam-se matriculados na única Escola da zona urbana que possui esta modalidade ensino, os demais estavam distribuídos entre três escolas da zona rural, sendo uma delas privada. 
Perguntariamos quais as circunstâncias presentes no universo social para definir as estratégias de inserção social via educação, e quais os significados diferenciais para a masculinidade, haja vista a presumida atração do mercado de trabalho e a percepção de que educação é assunto feminino nos lares. E, principalmente, de que "bom comportamento" - de um modo em geral e mais ainda na escola - não é exatamente "coisa de macho".

Desse modo podemos citar o depoimento de W.L.C.S. sobre sua trajetória escolar até o momento:

Eu estudei... tipo eu nunca estudei num colégio público, geralmente nunca fiz recuperação até o ano retrasado né... que eu perdi de ano; fui expulso do último colégio que eu estudei, fui um dos piores alunos do colégio na realidade, mas tá sendo uma trajetória boa. Eu... agora esse ano tô querendo estudar, mudar um pouquinho meu passado né? Tá manchado pra caralho.

Dados de outra pesquisa que realizamos em São Gonçalo, no Rio de Janeiro, entre jovens da comunidade popular do Jardim Catarina, indicam a importância do trabalho para a identidade de homens jovens, em associação à percepção de que o mesmo trabalho é o lugar da opressão (Pinho, 2010):

É porque a gente vê lá na rua, a gente passa e vê muitos jovens passando sabe, então, há uma certa discriminação por quem trabalha na rua, o pessoal fala pra caramba. Então a gente sofre de discriminação porque quando a gente arruma uma namorada: Pô , você trabalha de que? Pô, sou vendedor. Vendedor de que: (risos). Entendeu? É uma dificuldade muito grande, com preconceito com tudo; é bom a gente ter o trabalho da gente quando a gente terminou o segundo grau, a gente corre atrás também, mas só não tem retorno. (R. 23 anos)

Diferentemente do que Sansone (1996) parece apontar em seu trabalho, entretanto, entre os nossos entrevistados em São Gonçalo, a ética do consumo parece conviver com, e mesmo pressupor, a ética do trabalho como um valor central, não como um valor em si, mas como um meio de acesso justamente ao mundo do consumo e à dignidade pessoal. Trabalhar parece algo muito importante para esses jovens e mesmo definidor de seu lugar no mundo e de suas chances de felicidade. 
Outro aspecto em que poderíamos traçar um paralelo entre os Jovens no Jardim Catarina e em Cachoeira/São Félix refere-se à percepção do preconceito, notadamente com relação a homossexuais, que aparece com bastante ênfase nos dois casos, e que nos sugere a importância da estigmatização de homossexuais como meio de afirmação da identidade masculina "correta". Na verdade, a presença de homossexuais no campo em São Gonçalo, parecia ser uma coisa realmente comum. Tivemos oportunidade de identificar em várias circunstâncias a presença de homens e mulheres homossexuais. Na escola, no barzinho da esquina, em festas, etc. De certo ponto de vista existiria uma banalização do comportamento homossexual, associado a outras formas de comportamento "desviante".

PERGUNTA: E vocês têm algum amigo gay? Conhecem algum menino por aqui?

R: Ih, um montão!

V: Conheço dois que moram lá na rua e um do colégio que tem o cabelo enroladinho - 'ai gente' (imita o menino efeminado). (Pinho, 2010).

Mas talvez as coisas não sejam assim tão simples, e seríamos levianos em afirmar decididamente algo nesse sentido. Porque, inclusive existe claramente preconceito e rejeição, mesmo entre os rapazes que convivem habitualmente com homossexuais.

PERGUNTA: Você conhece alguém que seja homossexual? Como ele é? O que vc acha deles?

R.: Se eu conheço? Conheço. É, ele é branquinho, muito viadinho, tem muito por aqui por perto. Eu acho uma coisa muito feia, uma vez ou outra quando passa na rua, assim, o viadinho fica olhando, sempre mexe também; às vezes da vontade de voltar e tentar da um soco; sacanagem, eu acho isso muito feio. (R., 19 anos)

Ou na opinião de uma mulher: 


\begin{abstract}
PERGUNTA: O que vc acha da relação sexual entre pessoas do mesmo sexo?

C: O que acho? Como assim? Viado com viado?
\end{abstract}

PERGUNTA: Homem com homem, mulher com mulher... Você conhece? O que você acha disso?

C: Ah, sei lá! Como disse eu não tenho preconceito, mas acho que isso não poderia existir não.

PERGUNTA: Por que?

C: Porque não, se Deus fez o homem tem de ser homem, se fez a mulher tem de ser mulher. Não mulher gostar de mulher e homem gostar de homem. É muito feio (C., 20 anos).

Em Cachoeira e em São Félix, onde ainda não tivemos a oportunidade de realizar trabalho de campo na mesma extensão que em São Gonçalo, apontaríamos preliminarmente para que a percepção do preconceito não parece modificar-se por gênero a não ser pelo fato de que os meninos reconheceram com mais clareza situações em que foram agentes de discriminação, não só contra gays, mas também contra negros:

Já tipo assim, sobre gay, cheguei quase a agredir, tem um tempinho já, um gay e até discriminação racial velho, também, e eu que sou negro... sou quase negro, sou moreno. Tipo assim, eu humilhei um cara porque ele era preto, ele fez uma onda que eu não gostei, a gente terminou discutindo velho, aí saiu isso assim, mas foi da boca pra fora... hoje em dia eu falo com ele, ele sabe que não foi maldade, foi só num momento de raiva. (W., 18 anos)

\title{
Conclusão/Perspectivas
}

Como já apontamos, a pesquisa é exploratória e demanda maior aprofundamento. Estariamos na verdade definido melhor as nossas ques- 
tões a partir do trabalho de campo piloto, questões que esperamos poder desenvolver no seguimento de nossa investigação. Estas questões poderiam ser definidas como: Poderiamos considerar variáveis de gênero relevantes para definir as expectativas geracionais com relação à educação? As mães, de outra forma, investiriam mais na educação dos filhos, indistintamente se rapazes ou moças? Haveria, como de certa forma, intuímos a percepção de uma crise moral (de autoridade) que oporia as gerações? Tal crise assumiria diferenças por gênero?

Um dos pais entrevistados fala da falta de disciplina dos estudantes dos dias de hoje, argumentando que isso é reflexo da má educação doméstica, e responsabilizando as mães pela indisciplina dos filhos:

Os alunos hoje em dia estão muito mal educados e maltratam os professores inclusive com palavras de baixo calão, não sei porque isso está acontecendo, deve ser, eu acho que seja porque eles não tenha educação doméstica os alunos hoje, naquele tempo, no meu tempo inclusive, os professores tinham mais autoridade com os alunos, eu acho que é isso que ta acontecendo, não é que os professores esteja mal, mal, vamos dizer assim mal preparados, eles são, que minha mulher tem pós-graduação de português tudo e tal, pós-graduação ainda, e... mas ela chega reclamando, nervosa, é isso que acontece, eu acho que o que mudou realmente foi a educação das crianças em casa, foi a educação doméstica, que os meninos, a mãe pra se ver livre, manda pro colégio e quando reclamam a mãe não gosta ainda, mãe e vó, é isso que ta acabando com o ensino. (ênfase adicional).

O que nos aparece relativamente claro é que a escola parece ser um lugar desvalorizado pelos rapazes. E que apesar de que as meninas pareçam ter as mesmas expectativas profissionais dos rapazes, elas são mais exitosas na escola, o que não quer dizer, como vimos, que elas terão no futuro salários melhores. Os dados em Cachoeira e São Felix não permitem indicar uma conexão evidente entre gênero e sucesso escolar, mas em consonância aos dados para outros contextos, esperaríamos que assim fosse. Como e sob que condições dadas, do ponto de vista da desigualdade racial na região, é a questão que precisamos reconhecer nos próprios dados.

De um modo ou de outro, não temos dúvida que as variáveis de gênero são fundamentais para interrogar o enigma masculino na educação, e em especial o enigma dos rapazes negros, como vimos, os últimos na escala do desempenho escolar, com todas as graves consequências e conexões que esse insucesso parece guardar. 


\section{Referências}

Alvito, M. (2001). Homens e Meninos. En As Cores de Acari Uma Favela Carioca (pp. 105-138). Rio de Janeiro: Editora FGV.

Amar, P. (2003, agosto). Masculinidade e Curiosidades: Novos Olhares Interseccionais e Internacionais. Critica da Masculinidade, (1), 5-7.

Arihla, M., Unbehaum, S. e Medrado, B. (Orgs.). (2001). Homens e Masculinidades. Outras Palavras. São Paulo: Ecos/Editora 34.

Artes, A. e Carvalho, M. (2010) O trabalho como fator determinante da defasagem escolar dos meninos no Brasil: mito ou realidade? Cadernos Pagu (34),41-74.

Baudrillard, J. (1972). Para Uma Crítica da Economia Politica do Signo. São Paulo: Martins Fontes.

Bourdieu, P. e Passeron, J. (2010). A Reprodução. Elementos para uma Teoria do Sistema de Ensino. Petrópolis: Editora Vozes.

Butler, J. (2003). O Parentesco é Sempre Tido como Heterossexual? Cadernos Pagu, (21), 219-260.

Butler, J. (2004). Gender Regulations. En Undoing Gender (pp. 40-56). New York: Routledge.

Clarke, J., Hall, S., Jefferson, T. e Roberts, B. (1975). Subcultures, Cultures and Class. En Resistence Through Rituals. Youth Subcultures in Post-War Britain (pp. 9-74). London: Hutchinson in London / CCCS-University of Birminghan.

Ceccheto, F. (1997). As Galeras Funk Cariocas: Entre o Lúdico e o Violento. En Vianna, H. (Org.). Galeras Cariocas. Territórios de Conflitos e Encontros Culturais (pp. 95-118). Rio de Janeiro: Editora da UFRJ.

Ceccheto, F. (2004). Violência e estilos de masculinidade. Violência, Cultura e Poder. Rio de Janeiro: Editora FGV.

Cohen, C. (1999). The Boundaries of Blackness. Aids and the Breakdown of Black Politics. Chicago: The University of Chicago Press.

Cohen, C. (2001). Punks, Bulldaggers, and Welfare Queens. The Radical Potential of Queer Politics? En Blasius, M. (Ed.). Sexual, Identities, Queer Politics (pp. 200-227). Princeton and Oxford: Princeton University Press.

Collins, P. (2005). Black Sexual Politics. African Americans, Gender, and the New Racism. New York e London: Routledge.

Connel, R. W. (2005). Masculinities. Berkeley/Los Angeles: University of California Press.

Cornwall, A. e Lindsfarne, N. (1994). Dislocating Masculinity: Gender, Power and Anthropology. En Cornwall, A. e Lindsfarne, N. (Eds.) Dislocating Masculinity Comparative Ethnographies (pp. 11-47). London and New York: Routledge. 
Crenshaw, K. (1995) The Intersection of Race and Gender. En Critical Race Theory: The Key Writings that Formed the Movement (pp. 201-243). New York: New Press.

Dreyfus, H. e Rabinow, P. (1982). Towards a Theory of Discursive Pratice. En Michel Foucault: Beyond Structuralists and Hermeneutics (pp. 44-78). Chicago: The University of Chicago Press.

FUNDAJ. (2009). Transmissibilidade Intergeracional, Pobreza e Desigualdade Racial: visões e percepções. Recife.

Gilroy, P. (1987). Diaspora, Utopia and The Critique of Capitalism. En There Ain't No Black in The Union Jack (pp. 340-349). London: Hutchinson.

Hasenbalg, C. e Silva, N. (2003). Introdução. En Hasenbalg, C. e Silva, N. (Orgs.). Origens e Destinos. Desigualdades Sociais ao Longo da Vida (pp. 37-54). Rio de Janeiro: Topbooks.

Hooks, B. (2004). We Real Cool. Black Men and Masculinity. New Yortk: Routledge.

IPEA. (2009). Comunicado da Presidência. No. 36. PNAD 2008. Primeiras Análises: Juventude - Desigualdade Racial. Brasília.

Kimmel, M. (1998) A Produção Simultânea de Masculinidades Hegemônicas e Subalternas. Horizontes Antropológicos. Corpo, Doença e Saúde, (9), 103-118.

Maio, M. (1999). O Projeto Unesco e a agenda das Ciências Sociais no Brasil dos anos 40 e 50. Revista Brasileira de Ciências Sociais, 14 (41), 141 - 158.

Malebranche, M. D. (2006). 'Down Low' and The Politics of Blame. En The Time is Now. The State of AIDS in Black America (pp. 56-57). Black AIDS Institute.

Maldonado-Torres, N. (2007). Sobre la Colonialidad del Ser: Contribuciones al Desarrollo de un Concepto. En Castro-Gómez, S. e Grosfoguel, R. (Orgs.). El Giro Decolonial. Reflexiones para una Diversidad Epistémica mas allá del Capitalismo Global (pp.127-168). Bogotá: Siglo del Hombre Editores.

Mattos, C. (2006.). No Ritmo Neurótico: Cultura Funk e performances 'Proibidas' em Contexto de Violência no Rio de Janeiro. Dissertação (Mestrado em Ciências Sociais). Universidade do Estado do Rio de Janeiro.

Pinho, O. (2007) Lutas Culturais: Relações Raciais, Antropologia e Política no Brasil. Sociedade e Cultura, 10, 81-94.

Pinho, O. (2010). Heróis Ultra-Modernos: raça, gênero e modernização desigual na periferia do Rio de Janeiro. En Afro-Rio Século XXI - Modernidade e Relações Raciais no Rio de Janeiro (pp. 54-91). Rio de Janeiro: Garamond.

Quijano, A. (2007). Colonialidad del Poder y Clasificación Social. En CastroGómez, S. e Grosfoguel, R. (Orgs.). El Giro Decolonial. Reflexiones para una Diversidad Epistémica mas allá del Capitalismo Global (pp. 93-126). Bogotá: Siglo del Hombre Editores. 
Rosemberg, F. (2001). Educação Formal, Mulher e Gênero no Brasil Contemporâneo. Estudos Feministas, 9 (2), 515-540.

Sahlins, M. (1990) Estrutura e História. En Ilhas de História (pp. 172-194). Rio de Janeiro: Jorge Zahar Editor.

Sansone, L. (1996). Nem Somente Preto ou Negro: Sistemas de Classificação Racial no Brasil que muda. Afro-Ásia, 18, 165-187.

Souza, R. (2010, enero-junio). Rapazes negros e socialização de gênero: sentidos e significados de "ser homem". Cadernos Pagu (34), 107-142.

Stolke, V. (2006).O Enigma das Interseções: Classe, Raça, Sexo, Sexualidade. A Formação dos impérios transatlânticos do Século XVI ao XIX. Estudos Feministas, 14 (1), 15-42.

Strathern, M. (1996). For the Motion. 1989 Debate: The Concept of Society is Theoretically Obsolete. En Ingold, T. (Ed.). Key Debates in Anthropology (pp. 60-66). London and New York: Routledge.

Vainfas, R. (1997). Moralidades brasílicas: deleites sexuais e linguagem erótica na sociedade escravista. En Souza, L. (Org.). História da Vida Privada no Brasil (pp. 221-273) São Paulo: Companhia das Letras. 